\title{
Limited effects of traffic noise on behavioural responses to conspecific mating calls in the eastern sedge frog Litoria fallax
}

\author{
Charmaine P. E. Schou ${ }^{1} \cdot$ Alexis L. Levengood ${ }^{1} \cdot$ Dominique A. Potvin $^{1}$ (])
}

Received: 17 March 2021 / Revised: 25 July 2021 / Accepted: 29 July 2021 / Published online: 4 August 2021

() ISPA, CRL 2021

\begin{abstract}
Anthropogenic noise is a pervasive environmental feature across both urban and non-urban habitats and presents a novel challenge especially for acoustically communicating species. While it is known that some species adjust acoustic signals to communicate more effectively in noisy habitats, we know very little about how the receivers of these signals might be impacted by anthropogenic noise. Here, we investigated female and male Litoria fallax frogs' ability to distinguish between high- and low-quality acoustic signals during the presence of background traffic noise and without. We performed a controlled behavioural experiment whereby frogs were presented with simultaneously broadcasted attractive and unattractive calls from opposing directions, once with background traffic noise and once without. We found that females in particular chose the unattractive call significantly more often (and males significantly less often) when noise was being broadcast. This indicates that anthropogenic noise potentially affects receiver responses to acoustic signals, even when calls are not acoustically masked, with potential consequences for maladaptive mating behaviours and population outcomes.
\end{abstract}

Keywords Anthropogenic noise $\cdot$ Mate choice $\cdot$ Bioacoustics $\cdot$ Litoria $\cdot$ Urbanization

\section{Introduction}

Anthropogenic noise is a pervasive feature of the modern environment, constituting a relatively new selective pressure for acoustically communicating species. Recent studies have shown numerous effects of anthropogenic background noise on behaviour and physiology of terrestrial animals; however until recently, the majority of these studies have focused on birds (Potvin 2017). Expanding our understanding of how anthropogenic noise impacts other taxa has therefore become a priority. Anurans in particular are under immense pressure from global change patterns, and thus, increasing our knowledge about how human-altered soundscapes might be escalating this pressure is crucial for management and conservation.

Research into how anthropogenic noise affects wildlife has uncovered a myriad of consequences, especially for species that are highly acoustic. Many of these consequences

Dominique A. Potvin

dpotvin@usc.edu.au

1 Global Change Ecology Research Group, School of Science, Technology and Engineering, University of the Sunshine Coast, Queensland, QLD, Australia are a result of communication being disrupted by acoustic masking, whereby a signal broadcast within the same frequency bandwidth as noise cannot be detected (Bee and Swanson 2007; Barber et al. 2010). However, even when signals are not directly masked, noise may also constitute a distraction to signal receivers, resulting in incomplete communication and perception of signals (Senzaki et al. 2018). Thus, regardless of frequency, anthropogenic noise may impede processes that require attention to the information contained within acoustic signals such as mate choice.

Acoustic communication plays numerous roles in the process of reproduction for anurans. Males of many species engage in 'chorusing', vocally competing with each other by overlapping signals to gain female attention (Gerhardt and Huber 2002; Wells 2010; Bee 2015; Clulow et al. 2017). Males also pay attention to the acoustic signals of other males nearby to locate potential intraspecific competitors for physical combat (i.e. wrestling) to secure mating opportunities (Pombal et al. 1998; Tsuji and Matsui 2002). In addition, females differentiate between calls in order to locate and ultimately choose a suitable mate (Luo et al. 2016). Highquality or 'attractive' calls by males are often those which are energetically more costly, correlating with individuals' health, fitness, locality, parental care and/or increased egg 
fertilisation (Ryan et al. 1992; Prestwich 1994; Morrison et al. 2001; Gerhardt and Huber 2002; Felton et al. 2006; Jacobs et al. 2017; Kaiser et al. 2018). Exact call characteristics that are considered attractive such as frequency, call rate and tenure (number of nights spent at the chorus) differ between species (Morrison et al. 2001; Zhang et al. 2020). Thus, the detection and processing of conspecific calls is a crucial component of anuran mating behaviour.

While anurans have been shown to have a sophisticated auditory system to detect, recognize and discriminate between calls and sources of natural noise, anthropogenic noise has been shown to present a novel challenge in this process (Bee and Swanson 2007; Cunnington and Fahrig 2013; Tennessen et al. 2014; Senzaki et al. 2018). For example, anthropogenic noise has been observed to increase levels of stress hormones and impact female frogs' ability to locate signalling males (Tennessen et al. 2014). Distraction, aversion and avoidance behaviours have also been detected in female frogs subjected to high noise levels, whereby signal receivers showed delayed initiation and disorientation to signals in noise treatments (Senzaki et al. 2018). Females unable to locate males could result in reduced mating opportunities, and delayed reactions may increase susceptibility to predation (Read et al. 2014; Candolin and Wong 2019). One aspect of mate selection and interspecific communication that has been overlooked thus far in anurans, however, is how anthropogenic noise might impact the ability of individuals to discriminate between calls of varying quality.

In birds, anthropogenic noise has been found to impact the choices made by females according to song frequency (Halfwerk et al. 2011; Huet des Aunay et al. 2014). Female canaries Serinus canaria and great tits Parus major in noisy conditions tended to choose highfrequency songs that were more likely to be detected, even though low-frequency songs might indicate a better-quality individual (Halfwerk et al. 2011; Huet des Aunay et al. 2014). In cases where songs or calls are not necessarily masked by noise, however, it is unclear whether noise might impact individual decisions based on acoustic signals by obscuring information or distracting the receiver. Furthermore, research on birds suggests anthropogenic noise increases aggressive behaviour in males (termed the 'urban anger hypothesis') since males have been observed as being more responsive to stimuli when confronted with background noise (Phillips and Derryberry, 2018; Grabarczyk and Gill 2019). Increased aggression in anurans or less caution, especially to noise sources, could result in mortality (e.g. during combat, from approaching traffic or female frogs approaching aggressive males during mate selection). Again, however, we do not yet know whether or how male anurans might respond to noisy conditions in a competition context.
Here, we investigated female and male eastern sedge frogs' (Litoria fallax) mating behaviours, specifically their ability to distinguish high-quality (attractive) vs low-quality (unattractive) stimuli within a traffic noise context. Litoria fallax are commonly found in suburban ponds, but rarely in heavily urbanized habitat, thus making it an ideal species for investigating potential behavioural traits that may be impacted by noise. Experimentally, we broadcasted attractive/unattractive stimuli in two treatments: (1) the control with no background noise and (2) the experimental with traffic background noise. For the control trials, we predicted that females would prefer the attractive stimulus since they tend to be choosier (i.e., to gain fitness benefits). Responses of males were less predictable; however, based on a previous study on male túngara frogs (Physalaemus pustulosus), we might expect the males to show similar phonotaxis preferences to females, approaching the more attractive call (possibly to establish an advantageous chorus site: (Baugh and Ryan 2010)). For the experimental trial, we predicted that females and males would not make a clear choice or even show evidence of orientating towards a call source due to distraction, since their calls are not within masking range of traffic noise. We further analysed whether frogs remained stationary and turned towards a call only, or if they jumped towards the call under the same experimental conditions.

\section{Methods}

\section{Study species}

Litoria fallax, commonly known as the eastern sedge frog, is a small $(20-30 \mathrm{~mm})$ temperate anuran distributed along eastern Australia, from northern Queensland to southern New South Wales. They are a sexually dimorphic species; females are usually bigger than males, reaching a maximum size of 25-30 $\mathrm{mm}$ and males growing up to $20 \mathrm{~mm}$ (Hero et al. 2004; Upton et al. 2018). Both sexes vary in colour, from light green to brown fawn and can be found amongst vegetation throughout coastal areas such as swamps, streams, lagoons, ponds and farm dams (Hero et al. 2004). Breeding occurs across September-April (Spring/Summer months) (Hero et al. 2004); however, male frogs are known to call throughout the year (Upton et al. 2018).

Litoria fallax are commonly found in suburban ponds; however, they tend to be less common in highly urbanized areas, suggesting that there are environmental constraints on establishment and/or persistence in these areas. This study may therefore shed some light on whether or not noise acts as one of these constraints, if it is shown to negatively impact reproductive behaviours and/or choices. Despite being a relatively abundant species, there has been very little work done on its behavioural 
or evolutionary ecology. This experiment will thus also hopefully lay some groundwork for future research.

\section{Study area and sample collection}

Our study was conducted at two ponds at the University of the Sunshine Coast (USC) Sippy Downs campus (-26.717282, 153.064746). This site presented suitable field-testing conditions in that surrounding the ponds are flat, open areas ideal for setting up our trial arena. The ponds are enclosed with emergent reeds and vegetation.

During trials, the region was under a COVID-19 lockdown scenario, and thus, background levels were measured between 20 and $30 \mathrm{~dB}$. However, the study sites are normally subject to a certain level of background noise, ranging from 49 to $61 \mathrm{~dB}$ (Table 1). For context, background noise levels were measured after lockdown ended (i.e. during a period of 'normal' human activity) at $1 \mathrm{~m}$ above the ground with a sound level meter, A-weighted (Work Zone Sound Level and Temperature Meter EC-MSTM-01), at 18:30 for approximately $3 \mathrm{~min}$ and logarithmic averaged. We identified the sources of background noise as human voices, animals (e.g. frogs, birds, crickets) and vehicles (e.g. cars in parking lots and on main roads) (Table 1).

Female and male frogs were collected in the sites (Pond ' $E$ ' and Pond 'B') during nightly surveys. We conducted a total of 6 surveys between March 24 and April 2,2020 , in the evenings at 18:30 (approximately sunset) until 23:30 pm. We sampled different areas of the ponds each evening in an attempt to avoid recapturing the same individuals over multiple nights. Frogs were captured with small fish nets, $20 \mathrm{~cm}$ in size and/or by hand. Once captured, individuals were placed in a small, thin plastic bag containing a small amount of pond water, filled with air and transported in a bucket $\sim 10-25 \mathrm{~m}$ (varied by pond) to the trial ring. Individuals spent between 10 and $40 \mathrm{~min}$ involved in the experiment (from catch to release). We identified the sex of captured L. fallax based on thumb pad size (larger in males), body size and presence of a vocal sac.

Table 1 Background noise levels at the study sites, Pond B and E at the University of the Sunshine Coast Campus, Sippy Downs, Australia. Measurements were taken in 10-s increments across $3 \mathrm{~min}$ at

\section{Auditory sample collection}

Anthropogenic noise was represented by a continuous traffic noise playback, with peaks in noise levels throughout, previously recorded by DAP. The noise originates from a park in Melbourne, Australia, and contains a variety of vehicles and human traffic, typical of a city park. A graph depicting the relative energy of frequencies contained in the recording can be found in Online Resource 1 (ESM 1).

Two recordings were selected to represent $L$. fallax 'attractive' and 'unattractive' calls based on Litoria genus females' general preferences, since specific L. fallax preferences have not been previously specifically targeted in the experimental literature. As such, the attractive advertisement call was higher in frequency and call rate/peaks, while the 'unattractive call' was lower in frequency and call rate (Morrison et al. 2001). Thus, we sourced a recorded series of calls, confirmed to be from a L. fallax individual and recorded by J-M Hero, Griffith University as the attractive signal. We also sourced a call, confirmed to be from a $L$. fallax individual and recorded by $\mathrm{J}$ Hooper (Future-Plus Environmental) as the unattractive signal (Froggingaround. com 2020). Both recordings were from rural areas in Southeast Queensland (within $500 \mathrm{~km}$ of the study site) and were calibrated to play at the same amplitude as each other and comparable to natural levels $(70 \mathrm{~dB}$ at the centre of the testing arena, i.e. $60 \mathrm{~cm}$ away from the speaker). Background noise in each recording was reduced as much as possible using a high-pass filter in Audacity V2.4.2. Each recording lasted approximately $20 \mathrm{~s}$ in duration, and playbacks consisted of the calls on a loop for $2.25 \mathrm{~min}$. The average known dominant frequency of South-eastern Queensland Litoria fallax calls is within 4000-6000 Hz (Gan et al. 2021): our attractive and unattractive calls had average frequencies at $\sim 4290 \mathrm{~Hz}$ and $\sim 4020 \mathrm{~Hz}$ respectively and call rates of 11.4 and 7.5 calls per minute respectively. Spectrograms of the recordings can be found in Online Resource 2 (ESM 2).

\section{Experimental protocol}

We based our methods on previous mate choice tests (i.e. controlled playback experiments), commonly used on frogs

each site between 1800 and $2000 \mathrm{~h}$ during periods of 'normal' activity around campus (non-lockdown). Logarithmic averages of the data were calculated

\begin{tabular}{|c|c|c|}
\hline & Noise level average (dB-A) & Noise sources \\
\hline Pond B collected & 60.9 & L. fallax and other frogs calling, crickets, cars from road (far and nearby) \\
\hline Pond B trial area & 49.9 & Bus from USC terminal, cars from road, people, animals (cricket, gecko, birds) \\
\hline Pond E collected & 53.6 & $\begin{array}{l}\text { USC building, car noise from road and adjacent car park, L. fallax calling, swamp } \\
\text { hen, crickets }\end{array}$ \\
\hline Pond $\mathrm{E}$ trial area & 50.4 & People speaking (from practicing in adjacent sport fields), highway traffic, crickets \\
\hline
\end{tabular}


to test male/female behaviours and to measure anthropogenic noise impacts on wildlife (Tarlow and Blumstein 2007; Bee 2015). Since female anurans are naturally inclined to approach advertising males and assess quality, researchers can often base mate choice on female phonotaxis (where females orient to signals) (Bee 2015). Specifically, female frogs, when presented with multiple stimuli in choice tests (e.g., attractive vs unattractive calls), can indicate selection by phonotaxis towards one stimulus over the other in different scenarios (e.g. during periods of background noise or quiet) (Bee and Swanson, 2007; Gomez et al. 2009; Richardson and Lengagne 2010; Troïanowski et al. 2014; Bee 2015:20; Laird et al. 2016; Senzaki et al. 2018). Additionally, since anuran male-male competition constitutes vocal and/or fighting battles, playback experiments can stimulate calling behaviour (i.e. an evoked vocal response) or approaches to speakers (i.e. an evoked physical response) by focal males (Bee 2015). For example, male túngara frogs show phonotaxis behaviours echoing those of females by turning towards and approaching more attractive calls (Baugh and Ryan 2010). Although reasons for this reaction are still rather speculative, it may be that males wish to associate with other attractive males during a chorus in order to increase the likelihood of accessing more females themselves (Baugh and Ryan, 2010).

We set up a trial arena, which consisted of a small, rectangular pool $(1.2 \mathrm{~m}$ by $1.2 \mathrm{~m})$ filled with a small amount of pond water with a video camera situated above; speakers positioned at 0,90 and 180 degrees and red lighting at each corner and above (Fig. 1). Prior to tests, we measured the sound levels coming from each speaker at the bottom ('frog level') of the pool using a sound level meter (Work Zone Sound Level and Temperature Meter EC-MSTM-01) A-weighted and set at a sampling rate of 2 samples/s. This ensured that from the centre of the pool, the sounds coming from all speakers were consistent (i.e. L. fallax calls peaked at an average of around $70 \mathrm{~dB}$ and traffic noise averaged at around $60 \mathrm{~dB}$, consistent with the $60-80 \mathrm{~dB}$ range in previous studies) (Bee and Swanson 2007; Gomez et al. 2009; Richardson and Lengagne 2010; Troïanowski et al. 2014; Senzaki et al. 2018). Within the pool, outside sources of noise were measured to be approximately $20-30 \mathrm{~dB}$ when trials were completed, as outlined above.

We placed one female or male L. fallax frog in the arena where they were habituated for around $1-5 \mathrm{~min}$ (i.e., able to jump around the area until they were still) (habituation timing consistent with 1 min; Bee \& Swanson 2007 and 2 min; Troïanowski et al. 2014). Each frog was placed as close to the centre as possible (guided by a measuring tape across the middle) (Fig. 1). Once frogs were still in the middle of the pond, trials commenced.

During each trial, opposing speakers (i.e. at 0 and 180 degrees) played the attractive and unattractive calls. During

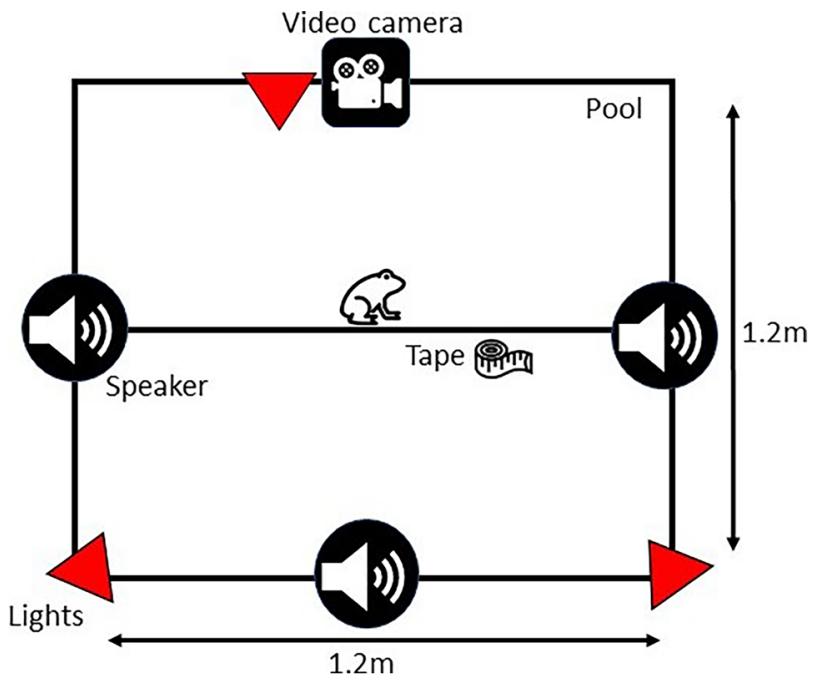

Fig. 1 Aerial diagram of the trial set up (pool) with speakers $(\times 3)$ taped to the sides at 0 (call speaker), 90 (traffic noise speaker) and 180 (call speaker) degrees. Video recording from above (tripod at the centre of pool). Measuring tape across the middle of the arena, torches with red polypropylene coverings taped to the corners and above and the addition of pond water $(\sim 0.5 \mathrm{~cm}$ depth $)$

the control trial, no other sounds were broadcast, and during the experimental trial, an additional speaker (positioned at 90 degrees) played traffic noise (Fig. 1). Frogs were exposed to their first trial for $2.25 \mathrm{~min}$ (duration of looped call), then were given a $0.5-3$-min break where no sounds were played, and to rehabituate them in the centre of the pool. The order of trials (i.e. no noise/noise) and the speaker (i.e. left or right) to play either the attractive or unattractive call were randomised for each individual and balanced over the entire experiment. When tested, neither speaker allocation nor trial order had an effect on choice or behaviour; thus, we determined our randomization was sufficient, and these were removed from any statistical analyses.

A total of 46 frogs were caught, sex identified and completed the behavioural test. Each frog was subject to both the control and experimental trials, for a total of 92 trials. Frogs were released back to their original location at their respective pond immediately after testing.

Written notes of frog behaviour (i.e. head movement, jumping, crawling or turning) were recorded during trials. Two researchers were present during the trials so that behaviours could be confirmed independently. Additionally, video footage was recorded from which our written notes were confirmed during later assessment. We assessed video footage without sound, thus enabling blind analysis with respect to treatment.

Phonotaxis through head scanning (sound detection) and/ or body movement toward stimuli is considered receptive (Morrison et al. 2001; Bee and Swanson, 2007; Gomez et al. 
2009; Trö̈anowski et al. 2014). Additionally, a choice is considered to have been made if individuals remain more than $20 \mathrm{~s}$ within the choice area. For example, Gomez et al. (2009) and Troïanowski et al. (2014) designated their experimental choice area by splitting their arena into halves when 2 calls were broadcast. Accordingly, our study deemed that a selection had been made when an individual turned either its head or whole body towards one of the two choice areas (towards each call-broadcasting speaker), or leapt towards the broadcasting speaker, and remained for more than $20 \mathrm{~s}$. Whether the frog remained stationary and turned its body/head towards a speaker or if it leapt towards one of the speakers was recorded. If the frog stood motionless or remained less than $20 \mathrm{~s}$ in any choice area (e.g., attempted to leave the arena at 90 degrees or 270 degrees), this was considered 'no selection', and if it spent more than $20 \mathrm{~s}$ in either of the two sections, then the section where it spent the most time was considered its 'choice' - all of these protocols were modelled on previous studies (Gomez et al. 2009; Troïanowski et al. 2014).

\section{Statistical analysis}

We used R Version 3.5.1 to create generalized linear mixed models (multinomial, logit-link function) testing the effect of traffic noise and sex (and their interaction) on whether frogs chose the unattractive call, attractive call or made no choice. Frog ID was included as a random effect in all models. We also initially included the two pond origins as a random factor in the models, but these were not significant, and the population may be considered contiguous (there is waterway connectivity between the two ponds); therefore, these were removed from the models. We used Wald tests (two-tailed $z$-tests) to test the significance of any model effects. We also tested the effect of noise and sex (and their interaction, as above) on whether frogs made no physical choice, stayed stationary but turned either their heads or bodies towards a sound source when making their choice, or jumped/leapt towards the call source when making the choice. For both response variables, if the interaction between sex and traffic noise was not significant and showed a negligible effect on the results as indicated by the test statistic, this interaction was removed from the model, and AIC values were compared between the models with and without the interaction. We took results from the final, best-fitting model based on these criteria (interaction non-significance and a better model fit according to AIC). AICs and overall model data are included in Online Resource 3 (ESM 3).

We then ran the models again, but this time, we removed any "non-selection" data, whereby choices were undetermined because the frog did not move (neither turning nor leaping towards the speakers), or leapt out of the arena without entering or facing either of the choice areas. This was to further pinpoint whether noise was having a direct effect on active choice, rather than potentially being a distraction or source of stress that caused a lack of choice. Finally, to compare our study subjects' behaviour to previous studies showing that animals tend to move away from noise sources during selection trials (Senzaki et al. 2018), we analysed whether individuals exhibited aversion or attraction to the noise source. Specifically, we tested whether both males and females moved away from the noise speaker (i.e. potential avoidance behaviour) or did not move (including the five trial instances where the frog moved towards the noise speakers - i.e., lack of noise avoidance behaviour).

\section{Results}

Out of a total of 46 frogs, we identified $30(65.2 \%)$ as female and $16(34.8 \%)$ as male. Across the 92 trials, 57 (62\%) resulted in a valid selection (attractive selected 27 times, unattractive selected 30 times) and 35 (38\%) resulted in no response. Frogs did not tend to move away from the noise speaker more during noise trials $(z=1.125, \mathrm{df}=1$, $P=0.289$ ).

We found that frogs were not more or less likely to choose unattractive or attractive calls or make no selection under different noise treatments (Table 2; Fig. 2). Furthermore, we found no differences between male and female frogs' phonotaxis responses (leaping or turning only) when including no choice, to different calls under different noise conditions (Table 2; Fig. 3).

When only definitive choices were considered (i.e., when "no choice" responses were removed), we found an overall interaction effect of traffic noise and sex on call choice (Table 3). Overall, unattractive calls were selected more often in the noise treatment: this pattern was driven

Table 2 Final three-way model results demonstrating potential effects of traffic noise and sex on (a) call choice (unattractive, attractive and no choice) and (b) response behaviour (stationary phonotaxis, movement towards speaker or no choice)

\begin{tabular}{lllll}
\hline & Coefficient & df1 & df2 & $P$-value \\
\hline a. Selection & & & & \\
Corrected model & 1.065 & 4 & 86 & 0.379 \\
Traffic noise & 0.664 & 2 & 86 & 0.518 \\
Sex & 1.510 & 2 & 86 & 0.227 \\
b. Response & & & & \\
Corrected model & 1.576 & 4 & 86 & 0.188 \\
Traffic noise & 0.753 & 2 & 86 & 0.474 \\
Sex & 2.520 & 2 & 86 & 0.086 \\
\hline
\end{tabular}


Fig. 2 L. fallax selections of attractive calls, unattractive calls or no selection in the control (no noise) and experimental (noise) treatments with $95 \%$ confidence intervals (CIs)

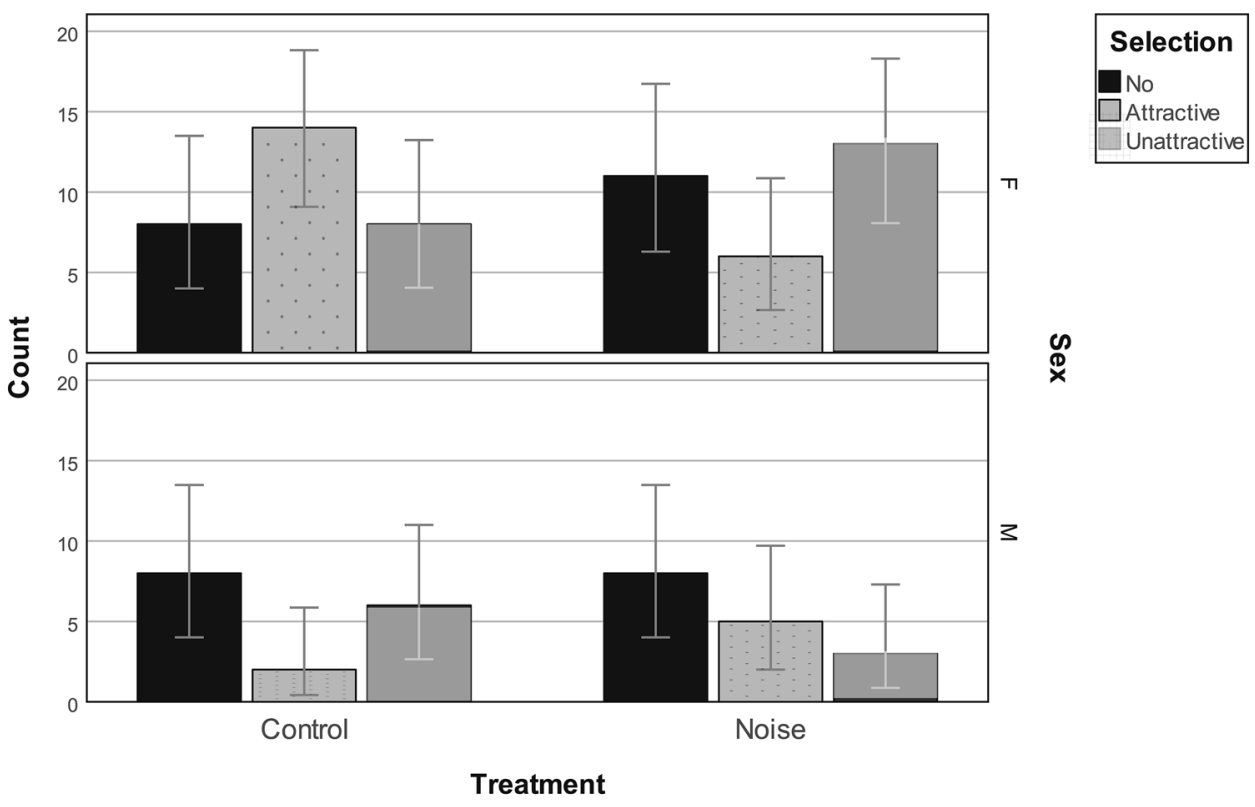

by females, while males in the noise treatment selected unattractive calls significantly less often (Table 3). We again did not find an effect of noise or sex on the type of behavioural response (jumping or turning) displayed by frogs when "no choice" responses were removed (Table 3). Parameter estimates for all final models can be found in the Online Resources (ESM 4) (Fig. 4).

\section{Discussion}

While literature concerning anthropogenic noise impacts on signal senders is now abundant, studies exclusively trialling signal receiver (female and male) responses within a traffic noise context are relatively rare. We conducted a classic choice experiment with two stimuli representing
Fig. 3 L. fallax behavioural responses to both call types in the control (no noise) and experimental (noise) treatments with $95 \%$ confidence intervals (CIs)

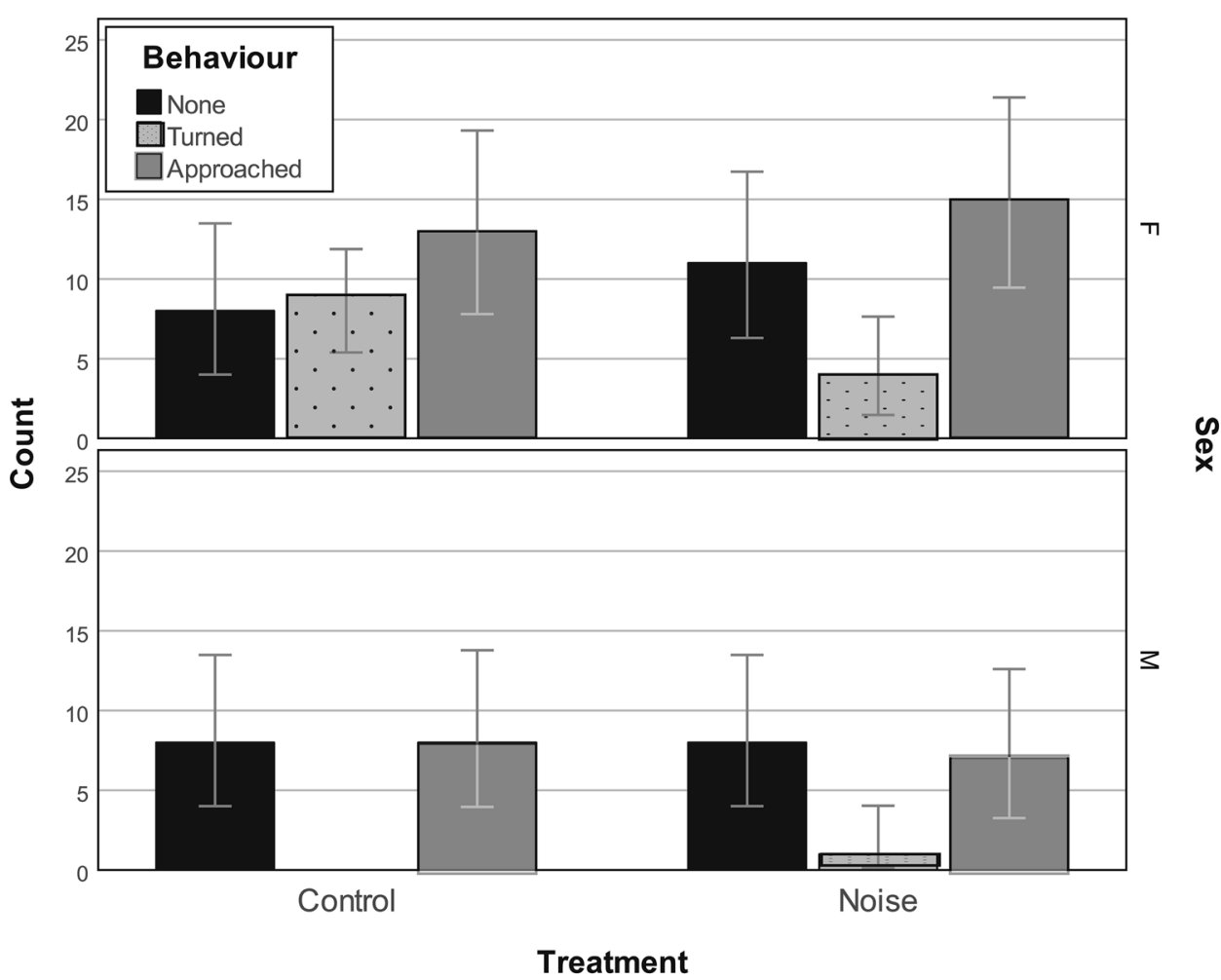


Fig. 4 L. fallax movement responses to both call types in the control (no noise) and experimental (noise) treatments with $95 \%$ confidence intervals (CIs)



Selection high- and low-quality male signals within two conditions: (1) no noise and (2) traffic noise. We found that, when a choice was made, female frogs specifically turned or leapt towards the unattractive low-quality male signal more when noise was present than when it was absent, whereas males tended to avoid this call during noisy periods. No other statistically significant differences between the trials were found. Therefore, our interpretations regarding the effects of background traffic noise on signal response are limited. We show evidence that receiver behaviours are impacted by the presence of noise; however, more research is needed to understand the mechanisms and potential importance of these findings.

Table 3 Final two-way model results demonstrating potential effects of traffic noise and sex on (a) call choice (attractive or unattractive) and (b) response behaviour (stationary phonotaxis or movement towards speaker)

\begin{tabular}{lllll}
\hline & Coefficient & df1 & df2 & $P$-value \\
\hline a. Selection & & & & \\
Corrected model & 2.089 & 3 & 53 & 0.113 \\
Traffic noise & 0.047 & 1 & 53 & 0.830 \\
Sex & 0.085 & 1 & 53 & 0.771 \\
Noise * sex & $\mathbf{5 . 2 7 8}$ & $\mathbf{1}$ & $\mathbf{5 3}$ & $\mathbf{0 . 0 2 6}$ \\
b. Response & & & & \\
Corrected model & 1.933 & 2 & 54 & 0.155 \\
Traffic noise & 0.907 & 1 & 54 & 0.345 \\
Sex & 3.096 & 1 & 54 & 0.087 \\
\hline
\end{tabular}

Typical mate choice theory expects females to select high-quality individuals to gain reproductive and/or survival benefits. Our finding that female frogs turned or leapt towards the unattractive male signal more during periods of traffic noise while males avoided this call during noise conditions may therefore indicate that traffic noise is affecting decision-making processes of signal receivers. Litoria fallax calls (both attractive and unattractive) are relatively high frequency $(5.02-6.4 \mathrm{kHz})$ and are thus not at risk of frequency masking by traffic noise $(1-3 \mathrm{kHz})$. Further, the attractive call used (determined using previous study data) was higher in frequency overall than the unattractive call, meaning that the potential that receivers might have been paying more attention to a more adaptive call that was acoustically displaced to avoid noise frequency (e.g. Huet des Aunay et al. 2014) is very unlikely. Potentially, females who selected the unattractive signal were able to hear both signals in each treatment but may have been distracted by traffic noise when opting to approach one of the calls. This echoes previous findings in Ezo brown frogs (Rana pirica), whereby females demonstrated a reduced ability to orient towards any male advertisement calls during noisy periods (Senzaki et al. 2018).

The exact mechanisms explaining why and how receivers may thus respond differently to different calls under varying noise conditions when acoustic masking is not an issue are unknown. One potential mechanism that has been posited is that of either acute or chronic increased stress. For example, 
traffic noise correlated with an increase in circulating corticosteroids (stress response hormone) in male tree frogs (Hyla arborea) (Troïanowski et al. 2017). A similar response in female wood frogs (Lithobates sylvaticus) was also found to affect their ability to make mating decisions (Tennessen et al. 2014). Similarly, female selection strength for high call rates specifically was found to be reduced when green tree frogs (Hyla cinerea) were administered with corticosteroids (Davis and Leary 2015). Based on these prior results, we might expect an increase in 'no choice' responses in this case, which we did not observe. It is possible that females in our population have habituated to high background noise levels (Table 1), and thus that our noise playback did not elicit a physiological stress response, and that higher intensity noises or noises of longer duration may do so; however, hormonal tests under varied conditions would be required to confirm this.

While noise might increase stress and impact behaviour in receivers directly, it may also do so indirectly. If signallers alter calls during noisy conditions as a direct result of stress, and these changes are detected by receivers, the altered calls may be interpreted as either more, or less, attractive than the original call. Interestingly, in male Boana faber, an increase in plasma corticosteroids is correlated with increased call rates (de Assis et al. 2012). In two other species (Hyla versicolor and Rana clamitans), call rates produced by males exposed to traffic noise decreased compared to no noise, and these calls were considered as attractive as calls produced during quiet periods by females under varying environmental conditions (Cunnington and Fahri 2013). We may therefore have seen a similar scenario in our own study: our unattractive call, displaying a decreased call rate, was possibly considered more attractive by individuals during noisy periods because it demonstrated a lack of stress under noise conditions or a more adapted call to the surrounding habitat. Investigating the relationship between noise, stress physiology and call rate and how this might affect female (and male) responses to calls under different scenarios in anurans would be a logical next step to understanding how these factors might be influencing individuals and populations.

It is possible that accounting for prior experience of individuals might also affect their responses to both calls under different noise conditions. Previous findings have shown that both males (Caorsi et al. 2017) and females (especially those originating from noisy sites; Senzaki et al. 2018) move away from experimental traffic noise. Unfortunately, we did not have an additional completely natural site from which to source focal frogs: all frogs in our population would have had some experience with moderate levels of anthropogenic noise (Table 1). Still, we did not observe any noise avoidance (through moving away from the speaker during noise trials) by the individuals in our study, indicating that this behaviour may be species-, population- or even habitat-specific.
Mate selection can be a difficult behaviour to study in an experimental scenario. We acknowledge that some of the limitations of our study may have prevented some results from being clear. For example, behavioural observations in anurans suggest that a number of variables (especially those in other modalities) that were not incorporated into our study may influence conspecific responses, including pheromones or vocal sac colouration. Interestingly, in some frogs, carotenoid colouration is negatively impacted by traffic noise, demonstrating that multiple modalities are important to consider in terms of both signallers and receivers when making choices in noisy habitats (Trö̈anowski et al. 2015). We also acknowledge that natural choruses tend to have more than two calling males available as choices to females - and that in fact, larger choruses may dampen any negative effects of traffic noise on individual signalling behaviour (Lengagne 2008). Whether receivers are more or less affected by traffic noise depending on chorus or local population size is still unknown, but an interesting potential future study.

One final aspect that should be considered for future studies is that of locally adapted calls. Many anuran calls have been found to contain characteristics that signify the caller's origin, like a regional dialect (Gomez et al. 2009; Laird et al. 2016; Jacobs et al. 2017; Kaiser et al. 2018; Wiens and Tuschhoff 2020). Additionally, both of the calls used in our experiment were non-local to the focal population; however, it is uncertain whether receivers might have been able to distinguish any characteristics that may have indicated clues about the caller's origin or history. It may be that under noisy conditions, individuals switch focus from acoustic to visual signals (Grafe et al. 2012); however, this strategy is not universal (Troïanowski et al. 2014). Behavioural responses such as approaching the calling speakers may have indicated a search for accompanying visual signals during the noise trials in our study; however, we did not observe any such behavioural strategy switching between treatments. Further studies would be able to quantify the value of multi-modal signalling in noisy environments in this species. We would also suggest that a better understanding of the overall reproductive behavioural ecology of this species, especially as relates to mate choice and advertisement calls, would be informative for future studies.

While L. fallax frogs, both female and male, used similar behaviours to indicate selection and responded to mating calls in the same way in noisy and non-noisy conditions, we still found that the sexes may be influenced by noise in terms of the calls they choose to pay attention to. Noise may thus influence mating decisions, if females in the wild choose lower quality mates (maladaptive mate choice) when confronted by anthropogenic noise (Bee 2015). If noise results in maladaptive mate selection, populations may suffer from reduced offspring quality and/or numbers (i.e., 
from low fertilisation success or fecundity) and ultimately decline (Candolin and Wong 2019). Even though we cannot infer additional anthropogenic noise effects on mate selection and offspring fitness or abundance from this initial study, we believe these questions would be well-served by future experimentation based on our initial findings. We recommend continuing studies on wildlife signal receiver responses so that further understanding of anthropogenic noise effects, especially on frog populations, can be attained.

Supplementary information The online version contains supplementary material available at https://doi.org/10.1007/s10211-021-00378-7.

Author contribution DAP conceived of the study and obtained all permits, ALL \& CPES completed all field work and data collection; CPES performed initial statistics, interpretation and wrote an early draft, and all the authors contributed to writing, dissemination, figure production and editing the final version of the manuscript.

Funding This work was financially supported by the Queensland Government Women's Research Assistance Program (grant awarded to DAP), the Environmental Legacy Foundation (bursary awarded to CPES), as well as internal funding from the University of the Sunshine Coast.

Data availability Raw transcribed observational data is included as supplementary electronic material.

\section{Declarations}

Ethics approval All animals were captured and handled in accordance with the University of the Sunshine Coast's Animal Ethics Committee's approved protocols (Permit ANS1859).

Competing interests The authors declare no competing interests.

\section{References}

Barber JR, Crooks KR, Fristrup KM (2010) The costs of chronic noise exposure for terrestrial organisms. Trends Ecol Evol 25:180-189. https://doi.org/10.1016/j.tree.2009.08.002

Baugh A, Ryan M (2010) Temporal updating during phonotaxis in male túngara frogs (Physalaemus pustulosus). Amphibia-Reptilia 31:449-454. https://doi.org/10.1163/017353710X518388

Bee MA (2015) Treefrogs as animal models for research on auditory scene analysis and the cocktail party problem. Int J Psychophysiol 95:216-237. https://doi.org/10.1016/j.ijpsycho.2014.01.004

Bee MA, Swanson EM (2007) Auditory masking of anuran advertisement calls by road traffic noise. Anim Behav 74:1765-1776. https://doi.org/10.1016/j.anbehav.2007.03.019

Candolin U, Wong BBM (2019) Mate choice in a polluted world: consequences for individuals, populations and communities. Philosophical Transactions of the Royal Society b: Biological Sciences 374:20180055. https://doi.org/10.1098/rstb.2018.0055

Caorsi VZ, Both C, Cechin S, Antunes R, Borges-Martins M (2017) Effects of traffic noise on the calling behavior of two Neotropical hylid frogs. PLoS One 12:e18334

Clulow S, Mahony M, Elliott L, Humfeld S, Gerhardt HC (2017) Near-synchronous calling in the hip-pocket frog Assa darlingtoni.
Bioacoustics 26:249-258. https://doi.org/10.1080/09524622. 2016.1260054

Cunnington GM, Fahrig L (2013) Mate attraction by male anurans in the presence of traffic noise. Anim Conserv 16:275-285. https:// doi.org/10.1111/j.1469-1795.2012.00598.x

Davis AG, Leary CJ (2015) Elevated stress hormone diminishes the strength of female preferences for acoustic signals in the green treefrog. Horm Behav 69:119-122. https://doi.org/10.1016/j. yhbeh.2015.01.005

de Assis VR, Navas CA, Mendonça MT, Gomes FR (2012) Vocal and territorial behavior in the Smith frog (Hypsiboas faber): relationships with plasma levels of corticosterone and testosterone. Comp Biochem Physiol a: Mol Integr Physiol 163:265-271. https://doi. org/10.1016/j.cbpa.2012.08.002

Felton A, Alford RA, Felton AM, Schwarzkopf L (2006) Multiple mate choice criteria and the importance of age for male mating success in the microhylid frog, Cophixalus ornatus. Behav Ecol Sociobiol 59:786-795. https://doi.org/10.1007/s00265-005-0124-6

Gan H, Zhang J, Towsey M, Truskinger A, Stark D, van Rensburg BJ, Li Y, Roe P (2021) A novel frog chorusing recognition method with acoustic indices and machine learning. Futur Gener Comput Syst 125:485-495. https://doi.org/10.1016/j.future.2021.06.019

Gerhardt HC, Huber F (2002) Acoustic Communication in Insects and Anurans: Common Problems and Diverse Solutions. J Acoust Soc Am 114:559

Gomez D, Richardson C, Lengagne T, Plenet S, Joly P, Léna J-P, Théry M (2009) The role of nocturnal vision in mate choice: females prefer conspicuous males in the European tree frog (Hyla arborea). Proceedings of the Royal Society b: Biological Sciences 276:2351-2358. https://doi.org/10.1098/rspb.2009.0168

Grabarczyk EE, Gill SA (2019) Anthropogenic noise affects male house wren response to but not detection of territorial intruders. PLoS One 14:e0220576

Grafe TU, Preininger D, Sztatecsny M, Kasah R, Dehling JM, Proksch S, Hödl W (2012) Multimodal communication in a noisy environment: a case study of the Bornean rock frog Staurois parvus. PLoS One 7:e37965 https://doi.org/10.1371/journal.pone.0037965

Halfwerk W, Bot S, Buikx J, van der Velde M, Komdeur J, ten Cate C, Slabbekoorn H (2011) Low-frequency songs lose their potency in noisy urban conditions. Proc Natl Acad Sci 108:14549-14554. https://doi.org/10.1073/pnas.1109091108

Hero JM, Meyer E, Clarke J (2004) Litoria fallax (errata version published in 2018). [Online.] Available at https://doi.org/10.2305/ IUCN.UK.2004.RLTS.T41091A10387698.en

Huet des Aunay, G., H. Slabbekoorn, L. Nagle, F. Passas, P. Nicolas, and T. I. Draganoiu. (2014) Urban noise undermines female sexual preferences for low-frequency songs in domestic canaries. Anim Behav 87:67-75. https://doi.org/10.1016/j.anbehav.2013.10.010

Jacobs LE, Vega A, Dudgeon S, Kaiser K, Robertson JM (2017) Local not vocal: assortative female choice in divergent populations of red-eyed treefrogs, Agalychnis callidryas (Hylidae: Phyllomedusinae). Biol J Lin Soc 120:171-178. https://doi.org/10.1111/ bij. 12861

Kaiser K, Boehlke C, Navarro-Pérez E, Vega A, Dudgeon S, Robertson JM (2018) Local preference encoded by complex signaling: mechanisms of mate preference in the red-eyed treefrog (Agalychnis callidryas). Behav Ecol Sociobiol 72:182. https://doi.org/10.1007/ s00265-018-2597-0

Laird KL, Clements P, Hunter KL, Taylor RC (2016) Multimodal signaling improves mating success in the green tree frog ( Hyla cinerea), but may not help small males. Behav Ecol Sociobiol 70:1517-1525. https://doi.org/10.1007/s00265-016-2160-9

Lengagne $\mathrm{T}$ (2008) Traffic noise affects communication behaviour in a breeding anuran, Hyla arborea. Biol Cons 141:2023-2031. https://doi.org/10.1016/j.biocon.2008.05.017 
Luo Z, Li C, Wang H, Shen H, Zhao M, Gu Q, Liao C, Gu Z, Wu $\mathrm{H}$ (2016) Male-male competition drives sexual selection and group spawning in the Omei treefrog, Rhacophorus omeimontis. Behav Ecol Sociobiol 4:593-605. https://doi.org/10.1007/ s00265-016-2078-2

Morrison C, Hero J-M, Smith WP (2001) Mate selection in Litoria chloris and Litoria xanthomera: Females prefer smaller males. Austral Ecol 26:223-232. https://doi.org/10.1046/j.1442-9993. 2001.01107.x

Phillips JN, Derryberry EP (2018) Urban sparrows respond to a sexually selected trait with increased aggression in noise. Sci Rep 8:7505. https://doi.org/10.1038/s41598-018-25834-6

Pombal JP, Martins M, Haddad CF (1998) Escalated aggressive behaviour and facultative parental care in the nest building gladiator frog, Hyla faber. Amphibia-Reptilia 19(1):65-73

Potvin DA (2017) Coping with a changing soundscape: avoidance, adjustments and adaptations. Anim Cogn 20:9-18. https://doi.org/ 10.1007/s10071-016-0999-9

Prestwich KN (1994) The energetics of acoustic signaling in anurans and insects. Am Zool 34:625-643. https://doi.org/10.1093/icb/ 34.6.625

Read J, Jones G, Radford AN (2014) Fitness costs as well as benefits are important when considering responses to anthropogenic noise. Behav Ecol 25:4-7. https://doi.org/10.1093/beheco/art102

Richardson C, Lengagne T (2010) Multiple signals and male spacing affect female preference at cocktail parties in treefrogs. Proceedings of the Royal Society b: Biological Sciences 277:1247-1252. https://doi.org/10.1098/rspb.2009.1836

Ryan MJ, Perrill SA, Wilczynski W (1992) Auditory tuning and call frequency predict population-based mating preferences in the cricket frog, Acris crepitans. Am Nat 139:1370-1383. https:// doi.org/10.1086/285391

Senzaki M, Kadoya T, Francis CD, Ishiyama N, Nakamura F (2018) Suffering in receivers: Negative effects of noise persist regardless of experience in female anurans. Funct Ecol 32:2054-2064. https://doi.org/10.1111/1365-2435.13130

Tarlow EM, Blumstein DT (2007) Evaluating methods to quantify anthropogenic stressors on wild animals. Appl Anim Behav Sci 102:429-451. https://doi.org/10.1016/j.applanim.2006.05.040
Tennessen JB, Parks SE, Langkilde T (2014) Traffic noise causes physiological stress and impairs breeding migration behaviour in frogs Conservation Physiology 2:1 https://doi.org/10.1093/conphys/ cou032

Trö̈anowski M, Condette C, Mondy N, Dumet A, Lengagne T (2015) Traffic noise affects colouration but not calls in the European treefrog (Hyla arborea). Behaviour 152:821-836. https://doi.org/ 10.1163/1568539X-00003255

Troïanowski M, Melot G, Lengagne T (2014) Multimodality: a way to cope with road traffic noise? The case of European treefrog (Hyla arborea). Behav Proc 107:88-93. https://doi.org/10.1016/j. beproc.2014.08.007

Troïanowski M, Mondy N, Dumet A, Arcanjo C, Lengagne T (2017) Effects of traffic noise on tree frog stress levels, immunity, and color signaling. Conserv Biol 31:1132-1140. https://doi.org/10. 1111/cobi. 12893

Tsuji H, Matsui M (2002) Male-male combat and head morphology in a fanged frog (Rana kuhlii) from Taiwan. J Herpetol 36(3):520-526

Upton R, Clulow S, Mahony MJ, Clulow J (2018) Generation of a sexually mature individual of the Eastern dwarf tree frog, Litoria fallax, from cryopreserved testicular macerates: proof of capacity of cryopreserved sperm derived offspring to complete development Conservation Physiology 6:1, coy04 https://doi.org/10. 1093/conphys/coy043

Wells KD (2010) The ecology and behavior of amphibians. University of Chicago Press, In.

Wiens JJ, Tuschhoff E (2020) Songs versus colours versus horns: what explains the diversity of sexually selected traits? Biol Rev 95:847864. https://doi.org/10.1111/brv.12593

Zhang F, Yuan C, Feng AS (2020) Female concave-eared torrent frogs prefer smaller males. J Zool 311:239-245. https://doi.org/10.1111/ jzo. 12775

Publisher's Note Springer Nature remains neutral with regard to jurisdictional claims in published maps and institutional affiliations. 